\title{
El Estatus jurídico de la Antártica ${ }^{1}$
}

\section{Legal Status of Antarctica}

\section{Gisselle Gajardo Flores}

gi.gajardo@gmail.com

Egresada de Derecho. Universidad de Chile.

Resumen: La comunidad internacional ha estado permanentemente en búsqueda de un rótulo adecuado para el sistema de administración que rige en la Antártica, toda vez que el Sistema del Tratado Antártico establece un régimen jurídico excepcional para un territorio terrestre que no es posible circunscribir en ninguna de las estructuras del derecho internacional clásico. Dentro de las propuestas, es posible encontrar conceptos derivados del derecho romano como el de res commune junto a conceptos más modernos como el patrimonio común de la Humanidad. El estatus jurídico de la Antártica debería describir adecuadamente la situación del territorio en relación a las cuestiones de soberanía, así como el acceso, destino y uso de sus recursos.

Palabras claves: Antártica - estatus jurídico - soberanía - territorio nacional - área internacional - res nullius - res commune - condominio - patrimonio común de la Humanidad.

\begin{abstract}
The international community has been constantly searching for an appropriate name for the Antarctic system of administration since the Antarctic Treaty System establishes an exceptional legal regime for a land territory that cannot be circumscribed in any of the structures of classical international law. Within the proposals, it is possible to find terms derived from Roman law such as res commune together with more modern concepts such as the common heritage of mankind. The legal status of Antarctica should adequately describe the situation of the territory in relation to matters of sovereignty, as well as the access, destination and use of its resources.
\end{abstract}

Keywords: Antarctica - Legal Status - Sovereignty - National Territory - International Area Res Nullius - Res Commune - Condominium - Common Heritage of Mankind.

1 Ponencia presentada en las Jornadas Chilenas de Derecho Antártico 2019, Facultad de Derecho, Universidad de Chile, 28 de marzo del 2019. 


\section{Introducción}

El descubrimiento tardío del continente antártico, la ausencia de población humana nativa y, sobre todo, el contexto político del período en el cual se presentaron las reclamaciones territoriales y sus respectivas delimitaciones, llevó a que los Estados, a fin de preservar la paz, consagraran en el Tratado Antártico (en adelante, TA) un régimen legal excepcional en el planeta para un área terrestre. De hecho, la Antártica es el único espacio terrestre en donde incluso su susceptibilidad para ser apropiado por un Estado soberano ha sido controvertida.

Si bien las normas que forman parte del Sistema del Tratado Antártico (en adelante, STA) son claras, no existe consenso a nivel internacional respecto al rótulo que debiese llevar el régimen actual que rige a la Antártica y sus recursos. Tal dificultad podría deberse precisamente a la imposibilidad de circunscribirlo dentro de las estructuras clásicas del derecho internacional.

La importancia de definir bien el estatus jurídico radica en la posibilidad de describir adecuadamente la situación del territorio en relación a las cuestiones de soberanía, así como el acceso, destino y uso de sus recursos.

A continuación, se presentan las diferentes propuestas que existen en la comunidad internacional respecto al estatus jurídico de Antártica.

\section{Antártica como territorio nacional}

Este estatus legal sería el que reconocerían los países que reclaman derechos soberanos en la Antártica. Si bien las controversias sobre las reclamaciones territoriales en este continente se encuentran suspendidas, éstas son plenamente reconocidas en el artículo IV del TA.

Artículo IV (1). Ninguna disposición del presente Tratado se interpretará:

(a) como una renuncia, por cualquiera de las Partes Contratantes, a sus derechos de soberanía territorial o a las reclamaciones territoriales en la Antártica, que hubiere hecho valer precedentemente;

Los Estados reclamantes fundan su derecho a ejercer jurisdicción en el área reclamada en su propio reclamo de soberanía territorial, y los Estados que no reconocen ningún reclamo rechazan la territorialidad como base para el ejercicio de la jurisdicción estatal (Lefeber, 1990: 
87). Sin embargo, como precisa Watts (1994: 119), existe una clara distinción entre ejercer soberanía sobre un área y solo reclamarla.

Si bien la relación entre soberanía y jurisdicción escapa del ámbito de este trabajo, es posible demostrar que los Estados sí ejercen jurisdicción de facto, aunque principalmente en un sentido amplio (véase Ferrada, 2018: 94-98).

Siguiendo al Dr. Luis Valentín Ferrada (2018), Reino Unido contempla un sistema jurídicoadministrativo complejo en el Territorio Antártico Británico, pues no solo posee un gobierno formalmente autónomo (aunque se encuentra radicado en Londres), sino que tiene competencias legislativas y judiciales propias. Noruega, en el Real Decreto de 26 de abril del 2013 promulgó un nuevo reglamento de protección ambiental y seguridad, estableciendo una jurisdicción con eficacia territorial sobre nacionales y extranjeros presentes en su territorio antártico. Australia, dando eficacia territorial a sus normas, demandó ante sus tribunales domésticos a balleneros japoneses que cazaban al sur de $\operatorname{los} 60^{\circ}$ de latitud sur. Tras desconocer a la autoridad australiana que los condenó, los japonenses fueron llevados ante la Corte Internacional de Justicia (en adelante, CIJ), fallándose también contra Japón el año 2014, aunque no por reconocer a Australia la facultad de regir con sus normas domésticas la actividad de no-nacionales en la Antártica, sino por considerar que la captura japonesa no se ajustaba a la Convención Internacional para la Reglamentación de la Caza de Ballenas (1946, en vigor 1948) ni se destinaba a fines científicos.

Si bien la mayoría de los Estados niega explícitamente la validez de los reclamos de soberanía territorial (Lefeber, 1990: 87; Watts, 1994: 120) lo cierto es que varios Estados no reclamantes han manifestado internamente a través de declaraciones el tener derechos en la Antártica. De manera ilustrativa mencionaré los siguientes ejemplos.

Perú: Si bien la Política Nacional Antártica peruana busca en parte "neutralizar u oponerse a las acciones o tendencias contrarias al régimen internacional para la Antártica actualmente vigente", también tiene como política "Apoyar y/o propiciar el establecimiento de todo régimen favorable a los intereses nacionales en los aspectos políticos, jurídicos, económicos y medioambientales". (D.S. 016-2002-RE del 27 de febrero de 2002)

Ecuador: La Asamblea Nacional Constituyente en sesión del 26 de febrero de 1967 declaró: "La República del Ecuador tiene derecho a la parte de la Antártida interceptada por los meridianos: $84^{\circ} 30^{\prime}$ y 96 $30^{\prime}$ de longitud al oeste de Greenwich, por estar situada en el Continente Sudamericano, con su territorio continental y su posición insular de las Islas Galápagos, con la soberanía del mar territorial de las doscientas millas, tanto en el continente como en las Islas Galápagos, y de acuerdo a la teoría reconocida por otros países para reivindicar sus derechos en la Antártica, de acuerdo con los conceptos geográficos de accesión por sectores polares, defrontación o enfrentación." (Moreano, 1990: 83) 
Estados Unidos: Si bien este país considera que cuenta con una base jurídica para sustentar un reclamo de soberanía, su abstención se debió a la intención de alejar a la Unión Soviética del hemisferio sur. El Programa Antártico de los Estados Unidos se basa en cuatro principios, dos de los cuales son "Los Estados Unidos no reconocen reclamaciones territoriales extranjeras" y “Estados Unidos se reserva el derecho de participar en cualquier uso futuro de la región". ${ }^{2}$

\section{Antártica como área internacional}

Es habitual que en la jerga académica del derecho internacional se tienda a mencionar la Antártica como territorio internacional. El término área internacional comprendería las áreas, territorios y espacios que se encuentran más allá de los límites de la jurisdicción nacional (Lefeber, 1990: 89). Se conoce universalmente como áreas internacionales la alta mar, los fondos marinos y el espacio ultraterrestre.

No se debe confundir con la noción de territorios internacionalizados. La idea de territorio internacionalizado usualmente se utiliza para referirse a las regiones cuya administración fue repartida por la comunidad beligerante, siendo los ejemplos más significativos de territorios internacionalizados Danzig, Trieste, Tánger y el Sarre (Marqués, 2010: 42).

Dado que la noción de área internacional ha sido construida sobre la idea de la no apropiación soberana por parte de los Estados, se ha discutido si la región antártica es un área internacional a propósito de las reclamaciones territoriales reconocidas en el artículo IV del TA.

Por otro lado, autores que restan valor a las reclamaciones territoriales y que destacan el cogobierno de facto que se ejerce por medio de las Reuniones Consultivas del Tratado Antártico (en adelante, RCTA), han preferido situar a la Antártica dentro de la idea de internacionalización sui generis, cuyo máximo referente corresponde a la antigua Berlín Occidental (Marqués, 2010: 42).

Otra de las razones que subyacen a la idea de área internacional, según una parte de la doctrina (Lefeber,1990), está dada por la existencia de un interés común o interés general por parte de la comunidad internacional en dichas zonas. Tal interés general correspondería al que tiene toda la Humanidad o la comunidad internacional en la protección del medioambiente antártico debido a su rol fundamental en el clima global.

2 National Science Foundation [en línea] < https://www.nsf.gov/geo/opp/antarct/uspolicy.jsp> [Consulta: 4 de marzo de 2019]. 
Es discutible que, en primer lugar, pueda afirmarse que la comunidad internacional, a través de los Estados, puedan representar el interés de la Humanidad, ya que esto sólo se ha reconocido a propósito de los intereses humanitarios ${ }^{3}$. Y, en segundo lugar, nos parece discutible que la existencia de un interés general de la Humanidad en Antártica justifique un régimen internacional de bienes.

Ciertamente, sí es posible distinguir entre una internacionalización jurídica y una internacionalización de facto, y en tal caso sólo sería posible afirmar que la Antártica se caracteriza por un co-gobierno internacional que se materializa a través de las RCTA. La internacionalización jurídica no es tal, debido a que el TA no establece precisamente una interdicción de soberanía.

\section{Antártica como territorio fideicometido}

En plena Guerra Fría y durante la década de delimitación de las reclamaciones territoriales, el presidente estadounidense Harry Truman planteó en 1948 dos propuestas sobre un régimen legal internacional sobre la Antártica a los siete países reclamantes: la primera propuesta consistía en poner la Antártica bajo el fidecomiso de la Organización de las Naciones Unidas (en adelante, ONU) de conformidad con el Capítulo XII de la Carta de las Naciones Unidas (1945). Y la segunda propuesta, que excluía a la otrora Unión Soviética, consistía en una internacionalización limitada de la Antártica por medio de un condominium (Díaz y Villamizar, 2014: 263).

El fideicomiso fue un régimen internacional de administración fiduciaria para los territorios que ya estuviesen sujetos a un mandato de la Sociedad de Naciones, con el objeto de preparar estos territorios para su autonomía o independencia

Según Díaz y Villamizar (2014: 19), el gran inconveniente de esta propuesta era netamente jurídico, pues según el artículo 76 de la CNU, el fidecomiso debe promover el desarrollo político, económico, social y educativo de la población que habita los territorios fideicometidos. Y dado el contenido sociológico de esta disposición, su aplicación era imposible en la Antártica.

En razón de lo anterior, la idea de la Antártica como territorio fideicometido quedó sólo en una propuesta histórica, rechazada por los países reclamantes por motivos jurídicos como el anteriormente señalado, y por ser un estatus esencialmente provisorio. También es posible advertir motivos políticos para el rechazo de esta propuesta, debido principalmente a la intención

3 Al respecto véase opinión consultiva de la CIJ de 28 de mayo de 1951 "Reservas a la Convención para la Prevención y Sanción del delito de Genocidio”. p. 15.

Número de página no utilizable para citar 
persistente de los países reclamantes de mantener alejada a la ONU de los temas antárticos, y, sobre todo, al carácter paternalista de la institución.

\section{Antártica como condominio}

En derecho internacional, existe un condominio cuando dos o más Estados ejercen en conjunto soberanía sobre un territorio (Samuels, 2008: 728), reconociéndose igualdad de derechos (Pinochet de la Barra, 1976: 113).

La segunda propuesta de Truman para la internacionalización de la Antártica bajo la forma de un condominio tenía como condición que cada país interesado renunciara a sus reclamaciones soberanas (Dodds, 2009: 33).

La aplicación de este estatus a la Antártica no es suficientemente abordada por la doctrina y más bien se rechaza debido a lo poco práctico que resulta su aplicación en el continente Antártico. Además, ello implicaría no reconocer la prevalencia del artículo IV del TA, que suspende la discusión sobre las reclamaciones soberanas. El condominio tiene un carácter temporal. Tan pronto una parte se sienta desfavorecida y mantenga su interés en el territorio, aprovechará las oportunidades para recuperarlo (Samuels, 2008: 728-729).

\section{Antártica como res nullius}

Básicamente, este es el estatus jurídico de los territorios o bienes que, sin ser de nadie, son susceptibles de apropiación individual por parte de algún Estado, o incluso por una persona natural o jurídica. Los res nullius pueden adquirirse por ocupación.

Este sería básicamente el estatus jurídico que habría tenido la Antártica antes de que los Estados se interesaran en ella, según defienden los países que mantienen reclamaciones territoriales. Por lo que puede ser adquirido por cualquiera de los medios originarios de adquisición territorial reconocidos por el derecho internacional.

Quienes defienden la idea de la Antártica como área internacional o res comunnes, rechazan que ella pueda o haya podido ser considerada como un territorio susceptible de apropiación soberana. 
Una errada doctrina interpreta que, "demostrado que los reclamos territoriales no son sostenidos por la comunidad internacional, el continente antártico es usualmente considerado como terra nullius" (Lefeber, 1990: 103). Esta afirmación necesariamente conduce a la consideración de la institución del reconocimiento de Estados como una condición necesaria para su existencia, siendo que la doctrina más aceptada (Briggs, 1949: 120) apunta a que el reconocimiento, como acto discrecional y político de un Estado reviste de un carácter declarativo y no constitutivo. Así se consagró en el artículo $3^{\circ}$ de la Convención sobre Derechos y Deberes de los Estados (1933).

Artículo 3. La existencia política del Estado es independiente de su reconocimiento por los demás Estados. Aun antes de reconocido el Estado tiene el derecho de defender su integridad e independencia, proveer a su conservación y prosperidad y, por consiguiente, de organizarse como mejor lo entendiere, legislar sobre sus intereses, administrar sus servidos y determinar la jurisdicción y competencia de sus tribunales.

El ejercicio de estos derechos no tiene otros límites que el ejercicio de los derechos de otros Estados conforme al Derecho Internacional.

En el mismo sentido, un tribunal arbitral mixto polaco-alemán había sostenido con anterioridad que:

$[\ldots]$ el reconocimiento de un Estado no es un elemento constitutivo sino meramente declarativo. [...]Es suficiente que ... [su] territorio tenga suficiente consistencia, aunque sus límites aún no se hayan determinado con precisión". (Caso Deutsche Continental Gas-Gesellschaft v. Estado Polaco, 1929: 336344).

No se debe olvidar que el TA suspende las controversias territoriales, mas no los derechos soberanos de los países ${ }^{4}$. Así, tampoco desecha la posibilidad de que otros Estados puedan reclamar derechos soberanos -mas no durante su vigencia-.

Es necesario precisar que, aunque no exista consenso respecto al estatus jurídico del continente antártico y pese a la existencia de convenciones y recomendaciones que imponen restricciones a la explotación de sus recursos, en el STA los recursos naturales de la región sí son considerados como res nullius (Lefeber, 1990: 85), pues las limitaciones que existen sobre la explotación de recursos antárticos son de carácter cualitativo -especies cuya explotación se encuentra prohibida o restringida, zonas de protección y de prohibición de actividad minera- y cuantitativa -cuotas de pesca-, pero no apuntan a un Estado en particular.

4 En efecto, el art. IV (1) del Tratado Antártico señala: "Ninguna disposición se interpretará como una renuncia, por cualquiera de las contratantes, a sus derechos de soberanía territorial o a las reclamaciones territoriales en Antártida que hubiere hecho valer precedentemente". 
Finalmente, conviene aclarar que el que los recursos sean res nullius no puede llevar a la conclusión de que el territorio en el cual se encuentran también lo sea. A modo de ejemplo, la libertad de pesca -restringida- en alta mar es una consecuencia del principio de libertad de navegación, y de esto no se puede deducir la posibilidad de apropiación por un Estado soberano de una porción de ella, no sólo porque un tratado internacional lo prohíba sino porque, precisamente, atentaría contra el principio de libertad de navegación.

\section{Antártica como res commune}

Para los romanos, se trataba de aquellas cosas que por su naturaleza pertenecían a todas las personas, y que, en consecuencia, no eran susceptibles de apropiación. Su uso era común y de acceso libre, ya que podían ser utilizadas por todos sin sufrir ningún tipo de deterioro o menoscabo. El principal motivo por el cual el derecho romano confirió el estatus de res comunnes al aire, los astros y el océano radicaría, precisamente, en el carácter inabarcable de sus dimensiones e inagotable de sus recursos (Solís Alvarado, 2012: 50), una cuestión que podría ser fácilmente rebatida en la actualidad.

Esta idea ha sido puesta en evidencia por su poca efectividad práctica y porque se enfrenta al problema que Hardin denominó "la tragedia de los comunes". Tal como señala Añaños (2014: 156), los bienes comunes como propuesta de una acción colectiva institucional "no son recomendables para solucionar los problemas de agotabilidad o depredación de recursos agotables o consumibles que están a libre disposición en el planeta, debido a su fracaso irremediable a causa de la naturaleza racional del hombre que tiende a su uso excesivo o abuso para procurar su propia maximización de la utilidad”.

\section{Antártica como reserva natural}

Se declara reserva natural o ecológica a las áreas que requieren ser protegidas por su riqueza o fragilidad de flora y fauna silvestre, asegurando su conservación en el tiempo. Es ante todo, un estatus que busca proteger a un ecosistema del deterioro o amenaza.

De conformidad con el Protocolo al Tratado Antártico sobre Protección del Medioambiente (1991, en vigor 1998), se establece la necesidad de un sistema global de protección del 
medioambiente en la Antártica y sus ecosistemas dependientes porque interesaría a la Humanidad en su conjunto.

En el artículo $4^{\circ}$ del Protocolo Medioambiental, se señala que este instrumento complementará al TA y no lo modificará ni enmendará. En consecuencia, al ser parte del STA, que regula la situación jurídica de la Antártica, se estaría consagrando a este continente como una reserva natural a través del artículo $2^{\circ}$ que declara:

"Las Partes se comprometen a la protección global del medio ambiente antártico y los ecosistemas dependientes y asociados y, mediante el presente Protocolo, designan a la Antártica como reserva natural, consagrada a la paz y a la ciencia".

La declaración de la Antártica como reserva natural no conlleva un régimen de exclusión de reclamaciones territoriales, puesto que esta normativa no puede ir en contra del artículo IV del TA. Cabe destacar en este sentido, que Francia y Australia abogaron por la declaración de reserva natural aun cuando ambos países son reclamantes del territorio antártico.

Debemos a su vez diferenciar el concepto de reserva natural con el de parque mundial, pues a pesar de que ambos otorgan la categoría de área protegida a un territorio, estableciendo obligaciones legales para su protección y conservación, este último implica la exclusión de soberanía, encontrándonos frente a un estatus jurídico que reemplaza la regulación actual que propone el STA.

Al menos tres ONG abogaron por la declaración de la Antártica como parque mundial, no obstante, prevaleció la idea de reserva natural:

"Greenpeace, el Fondo Mundial para la Naturaleza y la Coalición de la Antártica y de los Océanos Australes piden para la Antártica el estatuto de "parque mundial o reserva natural internacional" que regule la investigación científica, el turismo y la explotación pesquera, y prohíba la explotación de los recursos minerales, toda actividad militar o nuclear, la descarga de desechos tóxicos y radiactivos y la matanza de mamíferos marinos y aves" (Diario El País, 10 de octubre de 1989).

\section{Conclusiones}

El estatus jurídico actual de la Antártica es intencionadamente ambiguo, y responde al principal objetivo del TA de 1959, que era conciliar todos los intereses contradictorios que existían -y

Número de página no utilizable para citar 
siguen existiendo- en la Antártica. Así las cosas, la Antártica sería territorio nacional e internacional. Por una parte debe desecharse la teoría del reconocimiento de la generalidad de los Estados a las reclamaciones territoriales, admitiendo un fuerte elemento de internacionalidad de la Antártica, pero, por otra, debe admitirse que jurídicamente y en la práctica los Reclamantes tienen fundamentos en qué sustentar su posición.

Siguiendo a Orrego (1994: 597), la idea de área internacional bajo ningún punto de vista consagra una perpetuidad internacional $-\mathrm{o}$, lo que es lo mismo, de prohibición de soberanía-, sino que más bien se adopta un criterio de internacionalización funcional. En el mismo sentido, concluye Pureza (2002) que la Antártica se encontraría entre la territorialización y la internacionalización: una territorialización frágil, y una internacionalización políticamente limitada, debido a que se trata de una internacionalización funcional subyugada al desarrollo de la investigación científica.

\section{Referencias bibliográficas}

AÑAÑos MEZA, María Cecilia. "La doctrina de los bienes comunes de Francisco de Vitoria como fundamentación del dominio en el Nuevo Mundo”, Persona y derecho, 68 (2013): 103-137.

BriggS, Herbert W. "Recognition of States: Some Reflections on Doctrine and Practice". The American Journal of International Law, 43:1 (1949): 113-121.

DíAz, Regina I. y Villamizar, Fernando. "Uso pacífico de la Antártica como norma de ius cogens". Magallania, 42:1 (2014): 17-31.

DoDDS, Klaus. "La administración del continente polar: los orígenes geopolíticos del Tratado Antártico de 1959”. Istor: Revista de Historia Internacional, 10:39 (2009): 27-49.

FERRADA WALKER, Luis Valentín. "Five factors that will decide the future of Antarctica", The Polar Journal, 8:1 (2018): 84-109.

LEFEBER, René. "The exercise of jurisdiction in the Antarctic region and the changing structure of international law: The International Community and Common Interests". Netherlands Yearbook of Internation law, 21 (1990): 81-137.

MARQués RuedA, Efrén Gustavo. "La condición jurídica del Ártico y la Antártica: un asunto pendiente en la agenda jurídico-política de las relaciones internacionales contemporáneas". Revista de Relaciones Internacionales de la UNAM, 107 (2010): 39-65. 
Moreano, Hernan. "Ecuador Antártico - pasado y futuro”. Acta Antártica ecuatoriana, 2:1 (1990): 83-86.

Orrego Vicuña, Francisco. Derecho Internacional de la Antártida. Santiago: Dolmen Ediciones, 1994.

PINOChet De LA BARRA, Oscar. La Antártica Chilena: Estudio de nuestros derechos. Santiago de Chile: Editorial Andrés Bello, 1976.

PurezA, José Manuel. El patrimonio común de la humanidad, ¿hacia un derecho internacional de la solidaridad? Madrid: Trotta, 2002.

SAMUELS, Joel H. "Condominum Arrangements in International Practice: Reviving an Abandoned Concept of Boundary Dispute Resolution”. Michigan Journal of International Law, 29 (2008): 727-776.Solís Alvarado, Agustín. El concepto romano de res communes ómnium: estudio de su supervivencia en la conceptualización general del derecho. España: Editorial Académica Española, 2012.

WATTS, Arthur. International law and the Antartic treaty System. Cambridge: Grotius Publications Limited, 1992. 